\title{
Worry about Medical Care, Family Support, and Depression of the Elders in Urban China
}

Rongjun Sun

Cleveland State University, r.sun32@csuohio.edu

Follow this and additional works at: https://engagedscholarship.csuohio.edu/clsoc_crim_facpub

Part of the Demography, Population, and Ecology Commons, Medicine and Health Commons, and the Place and Environment Commons

How does access to this work benefit you? Let us know!

Publisher's Statement

(c) 2004 SAGE Publications

\section{Original Citation}

Sun, R. (2004). Worry about Medical Care, Family Support, and Depression of the Elders in Urban China. Research on Aging, 26(5), 559-585.

\section{Repository Citation}

Sun, Rongjun, "Worry about Medical Care, Family Support, and Depression of the Elders in Urban China" (2004).

Sociology \& Criminology Faculty Publications. 16.

https://engagedscholarship.csuohio.edu/clsoc_crim_facpub/16

This Article is brought to you for free and open access by the Sociology \& Criminology Department at EngagedScholarship@CSU. It has been accepted for inclusion in Sociology \& Criminology Faculty Publications by an authorized administrator of EngagedScholarship@CSU. For more information, please contact library.es@csuohio.edu. 


\title{
WORRY ABOUT MEDICAL CARE, FAMILY SUPPORT, AND DEPRESSION OF THE ELDERS IN URBAN CHINA
}

\author{
Rongjun Sun, Cleveland State University, Cleveland
}

\begin{abstract}
This study examines the role of family support in reducing the elders's depression in the face of the perceived inadequate public medical care in urban China. Using data from the Survey on Aging and Intergenerational Relations in Baoding City, this article investigates the overall depression level, somatic symptoms, and affective symptoms, respectively. The findings suggest that perceived inadequate public medical care, which results from dramatic changes in China's socioeconomic transformation, has a stressful impact on all measures of depression. Family support, by its structure and function, shows both direct and moderating effects in counteracting such stress from the public domain. In light of China's demographic transition, the state is called upon to adopt a comprehensive strategy in designing its socioeconomic development policy to meet the needs of an aging population.
\end{abstract}

Keywords: elderly; depression; medical care; family support; China

As the population ages rapidly throughout the world, more attention is directed toward the well-being of the elders in developing countries. The elderly population in China, the most populous and largest developing country in the world, is growing at an unprecedented rate: The proportion of persons aged 65 and older increased from $5.6 \%$ in 1990 to $7.0 \%$ in 2000 and is expected to be about $16 \%$ in 2030 (Zeng and Vaupe1 2002). Although the psychological well-being of the Chinese

AUTHOR'S NOTE: The author thanks Albert Hermalin and Martin Whyte for allowing use of the Baoding Survey data and Dennis Hogan, Susan Short, and David Lindstrom for their advice on the original draft of this article. The author thanks Andrzej Galecki for his suggestions on statistical modeling and appreciates insightful comments from SarahMatthews. Comments from the three anonymous reviewers are greatly appreciated. Address correspondence to Rongjun Sun, Department of Sociology, Cleveland State University, 2121 Euclid Ave., Cleveland, OH 44115; phone: (216) 687-4501; fax: (216) 687-9314; e-mail: r.sun32@csuohio.edu. 
elders has been explored in the literature, much of the attention has focused exclusively on the relationship between well-being and family support (Chen and Silverstein 2000; Chi and Chou 1999; Chou and Chi 2001; Gui et al. 1987; Krause and Liang 1993; Krause, Liang, and Gu 1998; Woo et al. 1994). As China undergoes significant social transformation, however, there is an opportunity to explore the impact of the public domain on well-being. The protective role of family support, both its structure and function, has rarely been examined in social context. Drawing on established literature and survey data collected in Baoding, China, in 1994, this study investigates the role of family support in maintaining psychological well-being of Chinese elders in the urban area where public medical care policy has undergone dramatic changes during an era of economic reform.

\section{Background}

\section{PUBLIC MEDICAL CARE}

The crucial role of public medical care programs in maintaining citizens' well-being has long been evident in developed nations. For example, since the establishment of Medicare in the United States in 1965, life expectancy has risen from 70 to 76 . Medicare has produced a significant impact on the health of the elderly population (Moody 2000). Although it lacks comprehensive welfare programs for all its citizens, as a developing country, China does provide limited welfare benefits to certain categories of the population, mainly urban workers and residents (Croll 1999). There has been a gradual shift away from a nearly universal medical care coverage in urban areas, however, and such a change has implications for the well-being of urban elders.

Before the economic reform instituted in the 1980 s in China, medical care coverage was almost universal in urban areas. In the planned economy, the welfare of workers and their dependents was virtually covered by work units. Workers were entitled to free health care for life, and they were reimbursed for as much as half of the health care costs of their dependents. Given that the majority of the urban population was associated with a work unit, almost all family members were beneficiaries of medical care coverage (Liang and Gu 1989). In the 
meantime, hospitals and health centers received most of their revenues from the government.

There has been a dramatic departure from the past practice since the economic reform in the early 1980 s. To reduce the financial burden of the state, the government cut back the health care benefits of state enterprises. Medical coverage is no longer totally borne by the work unit. Instead, it is shared by the local government, work unit, and individuals (Croll 1999; Davis 1989). Many money-losing enterprises, however, cannot provide any health benefit to their employees; therefore, individuals have to bear the costs on their own. As a result, access to health care, which was once universally provided, has become based largely on the patient's ability to pay. In addition, the hospital system was reformed. The government dramatically reduced its financing of hospitals, which are now required to make most of their revenue from the market. Hospitals tend to make profits by prescribing expensive drugs and by overusing high-technology tests (Hsiao and Liu 1996). Low-income households without any insurance risk bankruptcy if a member has a serious health problem. As consistently indicated by surveys in China, medical care, which for decades was not an issue in urban areas, in the past two decades has become a major concern of the public (Beijing Review 1997; Gui et al. 1987). Worry about not having enough money to cover medical care is a new source of stress among urban residents.

\section{FAMILY SUPPORT}

Families are the backbone of old-age support in China. Liang and $\mathrm{Gu}$ (1989) reported that of the 12 million Chinese elders who were physically dependent, the overwhelming majority were cared for by their families and that less than $0.5 \%$ were institutionalized. A more recent survey indicated that among those elderly Chinese who totally depended on others, $48 \%$ relied on their spouses and $40 \%$ relied on their children (Hong and Tracy 1999). The significant role of the family can be attributed to at least the following reasons.

First, taking care of the elders is strongly advocated by Confucian philosophy and traditional culture. Children are expected to place the interests of the whole family, their parents' welfare in particular, ahead of their own (Whyte 2003). It is a shared consensus that children should provide a wide range of support to their parents, including 
financial assistance, personal care, and emotional support. Second, due to the lack of financial independence of many elders and the limited social welfare programs, families inevitably take on the role of providing a safety net for older people. Finally, the value and practice of family support are reinforced by national laws. In light of the rapid population aging, on one hand, and the low economic level, on the other, social policies regarding old-age security in China place an emphasis on family support (Zhang 1997). The Law of Marriage, first established in 1950, modified in 1980, requires that children have the obligation to support their parents and prohibits abuse or abandonment (Zhu and Xu 1992). In 1996, China passed the Law on the Protection of Rights and Interests of the Elderly, which explicitly requires families to take responsibility for old-age support (Zhang 1997).

In sum, due to cultural, historical, and social policy reasons, the family plays a critical role in supporting the elders in China. But whether it plays a protective role in the face of inadequate medical care coverage has yet to be assessed.

\section{Framework and Hypotheses}

Studies of well-being in the presence of stress usually follow a stress-buffering framework (House 1981; House, Umberson, and Landis 1988; Pearlin 1989). Stress can result from either temporary events, such as an accident, bereavement, and unemployment, or chronic strains, such as poverty and chronic illness (Pearlin 1989). Chronic strains, due to their persistent nature, are recognized in the literature to have particularly deleterious effects on psychological wellbeing. Chronic strains erode one's self-esteem and mastery, and such losses in turn lead to depression (Pearlin et al. 1981).

The existent literature on the impact of stressful events on the depression of Chinese elders has focused almost exclusively on financial strain, which was consistently found to be significant (Chi and Chou 1999; Chou and Chi 2001; Krause and Liang 1993; Krause, Liang, and Gu 1998). Less well known, however, is the effect of worry about public medical care, which emerges as an issue of great concern in the changing Chinese society. The stressful effects of macro-social changes on human well-being, such as the economic recession in the United States in the mid-1970s and political changes in the former 
Soviet Union in the early 1990 s, have been recognized and documented in the literature (Cockerham 1999; Tausig and Fenwick 1999). Pei and Pillai's (1999) study shows that access to health care has a significant effect on the general happiness of Chinese elders.

Life events becoming stressful is a complex process (Bartlett 1998; Pearlin et al. 1981). Cognitive appraisal, a psychological process, is involved in assessing the impact of events. According to this theory, stress is related to the way individuals perceive and interpret external events in their surroundings. An event is stressful only when it is perceived as such by individuals. For example, a potentially stressful event, like retirement, may be perceived differently among individuals with different characteristics or under different social conditions (House and Robbins 1983).

Appraisals may be based on the actual harms or losses that have already occurred or on anticipated harms or losses (Bartlett 1998). That is, individuals who are worried about medical care may currently be experiencing hardships, for example, having difficulty in paying medical bills, placing financial burdens on themselves and their families, or hesitating to seek necessary medical care because of insufficient medical care coverage. Alternatively, such worries may indicate an anticipation of potential hardships, an anxious uncertainty about the future should problems arise, although nothing difficult has actually happened. In this sense, worry about medical care cannot be simply regarded as a special form of financial strain, because it can be independent of current financial circumstances. Those who have not encountered health problems and who are satisfied with their current income may still live in the shadow of an uncertain future. All these scenarios are stressful and conducive to depression.

In addition, in light of the social settings in urban China, worry about public medical care may better reveal the real situations of medical care coverage. As introduced above, after the economic reform, work units played a critical role in providing workers with medical care. Although some poorly performing work units could not afford such benefits, even among those that provided such benefits, actual coverage varied, differing on such things as the level of co-payment, the maximum amount of reimbursement, and coverage of relatives. To complicate the issue further, the promised health care coverage may not always be honored. Some work units, due to unexpected economic downturns or other reasons, indefinitely postponed the reimburse- 
ment of their employees' medical bills. Thus, objective measures on the availability of health care coverage or even on the level of coverage may not accurately describe the real situations. Worry about medical care may capture better the adequacy of medical care coverage.

As individuals face stressful events or situations, they tend to mobilize resources from their social surroundings to counter or reduce the adverse effects. Social support is a major moderator in buffering the effect of stress (Pearlin 1989; Pearlin et al. 1981). It may directly enhance the well-being (marginal effect) or moderate the effects of external stress (moderating effect). The moderating effect is manifest in an interaction effect between stress and social support (Wheaton 1985).

Studies on social support usually focus on two dimensions: structural and functional (Chen and Silverstein 2000; Lin, Ye, and Ensel 1999). The structural dimension refers to the existence of social relations or the potential availability of resources, such as marital status, number of children, and living arrangements. In a broader sense, it also covers other structural characteristics of the network, such as density, multiplexity, and homogeneity (House 1981; House et al. 1988). Functional measures assess tangible aid from the family network, such as instrumental and emotional support. They reflect resources that the elders actually use in dealing with various difficulties.

Studies have shown direct benefits of being embedded in social relations. Marital status has been found to be a significant factor affecting Chinese elders' psychological well-being (Chen and Silverstein 2000; Pei and Pillai 1999). Number of children represents the potential pool of resources that elderly parents can draw on when needed, but the effect of this variable is not consistent. Whereas Pei and Pillai (1999) found that more children were associated with a higher likelihood of feeling happy among the Chinese elders, such a fact was not found in Chen and Silverstein's (2000) study. Chi and Chou (2001) reported that the sheer number of relatives was not significantly related to depression among Chinese elders in Hong Kong; what mattered was the number of relatives they felt close to. Living with at least one adult child is usually assumed to facilitate the elders obtaining family help. However, empirical evidence in studies of Chinese elders is mixed. Both positive and nonsignificant effects were found in the literature (Chen and Silverstein 2000; Pei and Pillai 1999). 
Among functional measures, emotional support, which involves providing love, caring, and trust, is found to have a consistent effect on the psychological well-being in both Western and Eastern social settings (House 1981; Krause and Liang 1993; Pinquart and Sorensen 2000). For instance, Krause and Liang (1993), in their study of psychological distress of 2,721 Chinese elders, found that higher levels of emotional support were associated with lower depressed affect, lower level of somatic symptoms, and more positive self-evaluations. But the effects of instrumental support, like financial help, are mixed. Whereas some studies found receiving tangible assistance alleviated depression (Chi and Chou 2001), others found the effect was nonsignificant (Chen and Silverstein 2000; Krause and Liang 1993).

The moderating effect of family support was also reported in previous studies of Chinese elders. Krause et al. (1998) found that anticipated support in the future alleviated the adverse effect of financial strain on depression. Chou and Chi's (2001) study of the Chinese elders in Hong Kong showed that the negative impact of the number of stressful events on depressive symptoms were reduced for those elders with a higher level of social support.

Taken together, two hypotheses are to be tested in this study:

Hypothesis 1: Worry about public medical care, reflecting the inadequacy of medical care coverage, is associated with higher levels of depression among the Chinese elders.

Hypothesis 2: Family support, especially its functional measures, may directly enhance the psychological well-being of the elders and/or moderate the effect of worry about public medical care.

\section{Data and Method}

The data are from the Survey on Aging and Intergenerational Relations in Baoding City conducted jointly by Peking University and the University of Michigan in 1994. Baoding is a medium-sized city in northern China, about 100 miles from Beijing. According to the 1990 national census, there were 45,000 elderly people aged 60 or older in Baoding, about $7.5 \%$ of its total population of 600,000 . The Baoding survey is a two-stage probability survey. The target population was those residents aged 50 and older living in the urban districts, where a 
large proportion of female workers retire at age 50 and male workers at age 60 . At the first stage, 30 resident committees were selected. There were 11,389 eligible individuals identified, who constituted the sampling frame for the second stage of simple random sampling, which resulted in 1,160 individuals, of whom 1,002 were interviewed. The response rate was $86.4 \%$ (Whyte 2003). This analysis includes the 943 elders with at least one child who gave answers to all the relevant questions.

\section{DEPENDENT VARIABLES}

Depression is measured by a Chinese short version (14 items) of the Center for Epidemiologic Studies-Depression Scale (CES-D Scale), which originally comprised 20 items (Radloff 1977). Of the 14 items, 7 are related to somatic symptoms (worried, poor appetite, difficulty in sleeping, lack of concentration, full of energy, everything was an effort, unable to get things going), 3 are related to positive affective symptoms (happy, life was pleasant, this was the best time of life), 3 are related to depressive affects (felt lonely, depressed, life was a failure), and 1 item was related to interpersonal relations (felt disliked).

There is awareness in the literature about possible cross-cultural differences in the manifestation of depressive symptoms (Krause and Liang 1992). Kleinman (1977) found Chinese people in distress more expressive of somatic complaints than affective complaints. His study in Taiwan showed that the majority of mentally ill patients initially reported only somatic complaints. It was interpreted as commonly practiced suppression of affect in Chinese culture. In his review of the measurement of depressive experiences across cultures, Marsella (1987) made a similar observation: Somatic dimensions tend to be more salient than psychological dimensions in non-Western cultures. The distinction between affective and somatic symptoms has been highlighted in some empirical studies of the depression of Chinese elders (Krause and Liang 1993; Krause et al. 1998). This study first investigates the overall measure of depression, including all 14 items, then constructs separate measures for somatic and affective symptoms to examine whether they show different relationships with the covariates. ${ }^{1}$

All the items are assigned 1 to 4 to represent four levels: often, sometimes, rarely, and never. The negative items are recoded in a 
reverse order, so that a higher score for each item consistently reflects a higher level of depression. Reliability tests suggest good internal consistency of the overall depression score, somatic score, and positive affect score. The reliability coefficient alphas are $.84, .81$, and .73, respectively. But it is only .57 for the depressive-affect score. ${ }^{2}$ Therefore, in the analysis of specific symptoms, only somatic and positive affective symptoms (referred to as affective symptoms in the following text) are included. ${ }^{3}$

\section{INDEPENDENT VARIABLES}

The core independent variable of this study, worry about medical care, reflecting the adequacy of public medical care coverage, is based on responses to the question "Do you ordinarily worry that when you are sick that you will not be able to get good enough medical care?" Of the three possible responses, a lot, a little, and not at all, the first two are combined into a "worried" category, and the latter is coded as "not worried."

Family support is measured by the elders' marital status, number of children, living arrangements, receiving financial support, help with daily activities, in-kind gifts, and emotional support from children. The elders' marital status is classified into two categories: currently married and not married. Number of children is differentiated between one, two, three, four, and five or more. The living arrangements are composed of two large categories: living together with or separately from children. Among those who were living with their children, they are further differentiated by motives for doing so: for reasons of needing help or not. Those who were living separately from their children were further differentiated by their distance from the nearest child: in the same street neighborhood committee or in one less geographically proximate.

In the survey, the elders were asked if they were receiving money, in-kind gifts, and help with daily activities ${ }^{5}$ from their children. These three variables are dichotomous: yes or no. Responses to the question "In general, how satisfied are you with the emotional support that you receive from your children?" are coded as very satisfied, satisfied, and not satisfied. ${ }^{6}$

Demographic and socioeconomic characteristics of the elders included as control variables are gender (male, female), age (50-59, 60- 
69 , and 70 or older), educational attainment (illiterate, primary education, junior high school, and senior high school or above), and the elders' satisfaction with their family income (satisfied, unsatisfied).

Health status has been found to be consistently associated with psychological well-being (Chen and Silverstein 2000; Chi and Chou 2001; Chou and Chi 2001). A composite index of physical health is developed on the basis of three separate measures: self-rated health $(1=$ very poor, $2=$ not good, $3=$ average, $4=$ good, $5=$ very good $)$, the impact of any recent illness $(1=$ a lot, $2=$ a little, $3=$ no impact $)$, and capability $(1=$ unable to perform, $2=$ having a lot of difficulty, 3 = having a little difficulty, $4=$ having no difficulty) in performing the following activities: whether having difficulty walking 200 to 300 meters, climbing two or three flights of stairs, lifting as much as 10 kilograms, opening a tightly closed jar, standing for two hours, getting on a bus, and shopping. ${ }^{7}$ The final physical health index is a sum of the three separate scores after standardization, and the reliability coefficient alpha is .75 .

\section{ANALYSIS PLAN}

A series of linear regression models are used to analyze the overall level of depression. The first model includes only demographic and socioeconomic characteristics of the elders, physical health status, and worry about medical care. In the second model, measures of family support (marital status, the number of children, living arrangements, instrumental and emotional support) are added. The final model tests the moderating effect of family support by examining interactions between worry about medical care and family support measures.

Following the same strategy, a series of generalized multivariate regression models are applied to examine simultaneously the somatic and affective dimensions of depression. Such a joint modeling approach takes into account the possible correlation between them (Press 1972). The variance-covariance matrix of the two error terms, $\Sigma$, is a $2 \times 2$ matrix with the variance of somatic symptoms, $\sigma_{s}^{2}$, and the variance of affective symptoms, $\sigma_{\mathrm{a}}^{2}$, on the main diagonal. The covariance of the two dimensions of well-being, $\sigma_{s a}$, is located off the main diagonal. If the two dimensions are correlated conditional on the covariates included in the model, the covariance, $\sigma_{\mathrm{sa}}$, is expected 
to be statistically significant. Parameters of the model can be estimated by the generalized least square method (Littell et al. 1996; Press 1972).

Results

Table 1 describes characteristics of the surveyed elders. It is worth noting that about $40 \%$ of the elders worried about medical care. Such a relatively high proportion suggests that medical care, which was once provided almost universally to urban residents, has become a widespread social concern.

\section{OVERALL DEPRESSION}

Table 2 shows the results for the overall level of depression. Model 1 examines the effect of worry about medical care on depression controlling for demographic and socioeconomic characteristics. As hypothesized, worry about medical care is associated with higher level of depression among the Chinese elders, and such a relationship is statistically significant at the .001 level. Results also show that men are less depressed than women. Income satisfaction and physical health are inversely related to depression.

When family support measures, structural and functional, are added in Model 2, the negative effect of worry about medical care persisted but was reduced a little. Some family support measures show an enhancing effect on the elders' well-being. Being married reduces the level of depression by 1.76 points. Of all the family support measures, emotional support shows the most significant effect: compared with unsatisfied support, satisfied and very satisfied emotional support lessen the depression level by 4.73 and 6.56 points, respectively. Among other instrumental help measures, only receiving in-kind gifts is associated with lower level of depression. Financial support and help with daily activities show no effect at all. Living in the same street committee as children is associated with a lower level of depression compared with living with children in the same household. What is worth noting is that the number of children, contrary to the expectation, is positively related to the level of depression. Virtually all 
TABLE 1

Characteristics of All Analytical Variables for the Elderly $(N=943)$

\begin{tabular}{|c|c|}
\hline Variable & Percentage \\
\hline \multicolumn{2}{|l|}{ Age } \\
\hline $50-95$ & 50.5 \\
\hline $60-69$ & 37.7 \\
\hline $70+$ & 12.8 \\
\hline \multicolumn{2}{|l|}{ Gender } \\
\hline Male & 47.0 \\
\hline Female & 53.0 \\
\hline \multicolumn{2}{|l|}{ Education } \\
\hline Illiterate & 17.7 \\
\hline Primary school & 27.9 \\
\hline Junior high school & 26.1 \\
\hline Senior high school & 28.3 \\
\hline \multicolumn{2}{|l|}{ Family income satisfaction } \\
\hline Satisfied & 75.1 \\
\hline Unsatisfied & 24.9 \\
\hline \multicolumn{2}{|l|}{ Worry on medical care } \\
\hline Not worried & 61.4 \\
\hline Worried & 38.6 \\
\hline \multicolumn{2}{|l|}{ Marital status } \\
\hline Married & 88.7 \\
\hline Not currently married & 11.3 \\
\hline \multicolumn{2}{|l|}{ Total number of children } \\
\hline One & 6.1 \\
\hline Two & 23.2 \\
\hline Three & 34.9 \\
\hline Four & 20.4 \\
\hline Five or more & 15.4 \\
\hline \multicolumn{2}{|l|}{ Geographic proximity to children } \\
\hline Together not for help reason & 56.9 \\
\hline Together for help reason & 8.3 \\
\hline Same street committee & 12.4 \\
\hline Not same street committee & 22.4 \\
\hline \multicolumn{2}{|l|}{ Financial support } \\
\hline Yes & 24.1 \\
\hline No & 75.9 \\
\hline \multicolumn{2}{|l|}{ In-kind gifts } \\
\hline Yes & 33.8 \\
\hline No & 66.2 \\
\hline \multicolumn{2}{|l|}{ Help with daily activities } \\
\hline Yes & 31.5 \\
\hline No & 68.5 \\
\hline \multicolumn{2}{|l|}{ Emotional support } \\
\hline Very satisfied & 15.0 \\
\hline
\end{tabular}


TABLE 1 (continued)

\begin{tabular}{lcl}
\hline Variable & Percentage & \\
\hline Satisfied & 79.5 & \\
Not satisfied & 5.5 & $\mathrm{SD}$ \\
& $\mathrm{M}$ & 2.4460 \\
\hline Physical health & -0.0006 & 7.75 \\
Overall depression & 24.84 & 4.84 \\
Somatic symptoms & 13.04 & 2.38 \\
Positive affects & 5.56 & \\
\hline
\end{tabular}

TABLE 2

Parameter Estimates of the Linear Regression of Overall Depression $(N=943)$

\begin{tabular}{|c|c|c|c|}
\hline Covariate & Model I & Model 2 & Model 3 \\
\hline \multicolumn{4}{|l|}{ Age } \\
\hline \multicolumn{4}{|l|}{$50-59$ (reference) } \\
\hline $60-69$ & -0.09 & 0.12 & 0.21 \\
\hline $70+$ & -1.15 & -1.06 & -1.00 \\
\hline \multicolumn{4}{|l|}{ Gender } \\
\hline \multicolumn{4}{|l|}{ Female (reference) } \\
\hline Male & $-1.06 *$ & $-0.92^{*}$ & -0.85 \\
\hline \multicolumn{4}{|l|}{ Education } \\
\hline \multicolumn{4}{|l|}{ Illiterate (reference) } \\
\hline Primary school & -0.50 & -0.64 & -0.68 \\
\hline Junior high school & -0.86 & -1.02 & -1.13 \\
\hline Senior high school & -0.89 & -1.29 & $-1.45^{*}$ \\
\hline \multicolumn{4}{|c|}{ Income satisfaction } \\
\hline \multicolumn{4}{|c|}{ Not satisfied (reference) } \\
\hline Satisfied & 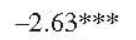 & 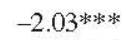 & -1.99 水冰 \\
\hline Physical health & $-1.33^{\text {水冰决 }}$ & -1.29 **** & -1.29 **** \\
\hline \multicolumn{4}{|c|}{ Worry on medical care } \\
\hline \multicolumn{4}{|c|}{ Not worried (reference) } \\
\hline Worried & 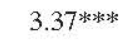 & $2.94 * * * *$ & 3.55 \\
\hline \multicolumn{4}{|c|}{ Marital status } \\
\hline \multicolumn{4}{|c|}{ Currently not married (reference) } \\
\hline Currently married & & $-1.76^{*}$ & $-1.77 *$ \\
\hline \multicolumn{4}{|l|}{ Number of children } \\
\hline \multicolumn{4}{|l|}{ One child (reference) } \\
\hline Two children & & $2.08 *$ & 0.23 \\
\hline Three children & & $2.71 * *$ & 0.77 \\
\hline Four children & & 1.51 & -0.73 \\
\hline Five or more & & $2.18^{*}$ & -0.50 \\
\hline
\end{tabular}


TABLE 2 (continued)

\begin{tabular}{|c|c|c|c|}
\hline Covariate & Model I & Model 2 & Model 3 \\
\hline \multicolumn{4}{|l|}{ Living arrangements } \\
\hline \multicolumn{4}{|l|}{ Together not for help (reference) } \\
\hline Together for help & & -0.57 & -0.64 \\
\hline Same street committee & & $-1.29 *$ & -1.20 \\
\hline Not same street committee & & -0.14 & -0.20 \\
\hline \multicolumn{4}{|l|}{ Financial support } \\
\hline \multicolumn{4}{|l|}{ No (reference) } \\
\hline Yes & & -0.03 & 0.02 \\
\hline \multicolumn{4}{|l|}{ In-kind gifts } \\
\hline \multicolumn{4}{|l|}{ No (reference) } \\
\hline Yes & & $-1.29 *$ & $-1.20^{*}$ \\
\hline \multicolumn{4}{|l|}{ Help with daily activities } \\
\hline \multicolumn{4}{|l|}{ No (reference) } \\
\hline Yes & & 0.09 & 0.12 \\
\hline \multicolumn{4}{|l|}{ Emotional support } \\
\hline \multicolumn{4}{|l|}{ Not satisfied (reference) } \\
\hline Satisfied & & $-4.73^{* * *}$ & -1.71 \\
\hline Very satisfied & & $-6.56^{* * * *}$ & -2.71 \\
\hline \multicolumn{4}{|l|}{ Interaction with worry on medical care } \\
\hline Two Children-Worried & & & 3.54 \\
\hline Three Children-Worried & & & 3.52 \\
\hline Four Children-Worried & & & $3.96^{*}$ \\
\hline Five or More Children-Worried & & & $5.37^{\text {*** }}$ \\
\hline Satisfied Emotional Support-Worried & & & $-4.03^{*}$ \\
\hline Very Satisfied Emotional Support-Worried & & & $-7.24^{\text {*** }}$ \\
\hline$R^{2}$ & .34 & .39 & .40 \\
\hline
\end{tabular}

${ }^{*} p<.05 .{ }^{* *} p<.01 .{ }^{* * * *} p<.001$.

the elders with more than one child exhibited higher depression than those with only one child.

Model 3 incorporates the interactions between family support measures and worry about medical care. It tests the moderating effects of family support, investigating whether the deleterious impact of worry about medical care falls differentially on the elders with different levels of family support. Preliminary analyses show that only the interactions between the number of children, emotional support, and worry about medical care are statistically significant for both overall and separate measures of depression; therefore, only these two sets of interactions are included in the final models.

In Model 3, the two sets of interactions show opposite effects on the elders' depression. As the number of children increases, the impact of 
worry about medical care on the level of depression also increases. This interaction effect becomes significant for the elders with four, five, or more children. In contrast, the impact of worry about medical care is greatly reduced among those elders with a higher level of emotional support: decreased by 4.03 and 7.24 points for those with satisfied and very satisfied emotional support, respectively.

The effects of the control variables remain consistent across these models, except that the advantage of the highest educational group becomes more visible in the last model.

JOINT MODELS OF SOMATIC AND AFFECTIVE SYMPTOMS

The results of the simultaneous modeling of somatic and affective symptoms, presented in Table 3 and Table 4, respectively, show both similar and different patterns between these two dimensions.

The similarities are the following: First, worry about medical care has a significant effect on both somatic and affective dimensions of depression, even when demographic, socioeconomic characteristics and physical health status are controlled for. Second, the effect of marital status is not significant in both models. Third, among instrumentalsupport measures, financial support and help with daily activities are related to neither somatic nor affective symptoms. Fourth, stronger emotional support is associated with a lower level of depression of both symptom dimensions in Model 2. Emotional support also shows a significant moderating effect on both somatic and affective depressive symptoms in Model 3. And this interaction effect is consistent with that for the overall depression measure: the higher the level of emotional support, the greater the reduction of the impact of worry about medical care on depression.

The differences between the two symptoms are the following: First, although it directly affects somatic symptoms, number of children shows a moderating effect on affective symptoms similar to it on the overall depression score. Second, although it is not related to somatic symptoms, receiving in-kind gifts is related to a lower level of affective symptoms. Third, although living arrangements do not show strong effects on both sets of symptoms, having children living in the same street committee, in comparison with those living together or living too far from children, is linked with lower somatic depression. 
TABLE 3

Parameter Estimates for Somatic Symptoms of the Joint Model

$(N=943)$

\begin{tabular}{|c|c|c|c|}
\hline Covariate & Model I & Model 2 & Model 3 \\
\hline \multicolumn{4}{|l|}{ Age } \\
\hline \multicolumn{4}{|l|}{ 50-59 (reference) } \\
\hline $60-69$ & 0.21 & 0.54 & 0.56 \\
\hline $70+$ & -0.16 & 0.21 & 0.24 \\
\hline \multicolumn{4}{|l|}{ Gender } \\
\hline \multicolumn{4}{|l|}{ Female (reference) } \\
\hline Male & $-1.32^{\text {*冰水 }}$ & 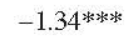 & $-1.30^{\text {*冰水 }}$ \\
\hline \multicolumn{4}{|l|}{ Education } \\
\hline \multicolumn{4}{|l|}{ Illiterate (refrence) } \\
\hline Primary school & 0.00 & -0.08 & -0.11 \\
\hline Junior high school & -0.44 & -0.59 & -0.64 \\
\hline Senior high school & -0.81 & $-1.04 *$ & $-1.10^{*}$ \\
\hline \multicolumn{4}{|l|}{ Income satisfaction } \\
\hline \multicolumn{4}{|l|}{ Not satisfied (reference) } \\
\hline Satisfied & $-0.92 * *$ & $-0.75^{*}$ & $-0.72 *$ \\
\hline Physical health & 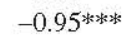 & -0.93 *水米 & 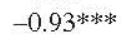 \\
\hline \multicolumn{4}{|l|}{ Worry on medical care } \\
\hline \multicolumn{4}{|l|}{ Not worried (reference) } \\
\hline Worried & $1.58 * * *$ & $1.40 * * *$ & 1.96 \\
\hline \multicolumn{4}{|c|}{ Marital status } \\
\hline \multicolumn{4}{|c|}{ Currently not married (reference) } \\
\hline Currently married & & -0.13 & -0.12 \\
\hline \multicolumn{4}{|l|}{ Number of children } \\
\hline \multicolumn{4}{|l|}{ One child (reference) } \\
\hline Two children & & $1.23^{*}$ & 0.64 \\
\hline Three children & & $1.58^{\text {*2* }}$ & 0.90 \\
\hline Four children & & 0.52 & -0.08 \\
\hline Five or more & & 0.96 & 0.29 \\
\hline \multicolumn{4}{|c|}{ Living arrangements } \\
\hline \multicolumn{4}{|c|}{ Together not for help (reference) } \\
\hline Together for help & & -0.47 & -0.48 \\
\hline Same street committee & & $-0.92 *$ & $-0.89^{*}$ \\
\hline Not same street committee & & -0.14 & -0.17 \\
\hline \multicolumn{4}{|l|}{ Financial support } \\
\hline \multicolumn{4}{|l|}{ No (reference) } \\
\hline Yes & & 0.06 & 0.11 \\
\hline \multicolumn{4}{|l|}{ In-kind gifts } \\
\hline \multicolumn{4}{|l|}{ No (reference) } \\
\hline Yes & & -0.40 & -0.45 \\
\hline \multicolumn{4}{|l|}{ Help with daily activities } \\
\hline \multicolumn{4}{|l|}{ No (reference) } \\
\hline Yes & & 0.17 & 0.19 \\
\hline
\end{tabular}


TABLE 3 (continued)

\begin{tabular}{|c|c|c|c|}
\hline Covariate & Model I & Model 2 & Model 3 \\
\hline \multicolumn{4}{|l|}{ Emotional support } \\
\hline \multicolumn{4}{|l|}{ Not satisfied (reference) } \\
\hline Satisfied & & $-1.73^{* *}$ & -0.58 \\
\hline Very satisfied & & $-2.57 * * * *$ & -0.97 \\
\hline \multicolumn{4}{|l|}{ Interaction with worry on medical care } \\
\hline Two Children-Worried & & & 1.11 \\
\hline Three Children-Worried & & & 1.34 \\
\hline Four Children-Worried & & & 1.03 \\
\hline Five or More Children-Worried & & & 1.19 \\
\hline Satisfied Emotional Support-Worried & & & -1.54 \\
\hline Very Satisfied Emotional Support-Worried & & & $-3.23 *$ \\
\hline$\sigma_{s}^{2 a}$ & $14.64^{* * * *}$ & 14.28 ****⿰冫⿰亅⿱丿丶丶 & $14.25^{\text {*冰水 }}$ \\
\hline$\sigma_{a}^{2 a}$ & $4.78^{*} * * *$ & 4.63 **** & $4.57^{\text {**** }}$ \\
\hline$\sigma_{s a}{ }^{a}$ & $1.94^{* * * *}$ & $1.75^{* * * *}$ & $1.70^{\text {**** }}$ \\
\hline
\end{tabular}

TABLE 4

Parameter Estimates for Affective Symptoms of the Joint Model $(N=943)$

\begin{tabular}{|c|c|c|c|}
\hline Covariate & Model I & Model 2 & Model 3 \\
\hline \multicolumn{4}{|l|}{ Age } \\
\hline \multicolumn{4}{|l|}{ 50-59 (reference) } \\
\hline $60-69$ & -0.17 & -0.14 & -0.09 \\
\hline $70+$ & $-0.85^{\text {*冰水 }}$ & -0.79 *** & 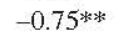 \\
\hline \multicolumn{4}{|l|}{ Gender } \\
\hline \multicolumn{4}{|l|}{ Female (reference) } \\
\hline Male & $0.34 *$ & $0.34 *$ & $0.35^{*}$ \\
\hline \multicolumn{4}{|l|}{ Education } \\
\hline \multicolumn{4}{|l|}{ Illiterate (reference) } \\
\hline Primary school & -0.03 & -0.11 & -0.12 \\
\hline Junior high school & 0.13 & 0.04 & 0.02 \\
\hline Senior high school & 0.34 & 0.19 & 0.15 \\
\hline \multicolumn{4}{|c|}{ Income satisfaction } \\
\hline \multicolumn{4}{|c|}{ Not satisfied (reference) } \\
\hline Satisfied & $-1.03 * * *$ & $-0.85^{* * * *}$ & $-0.83^{* * *}$ \\
\hline Physical health & $-0.21^{* * * * *}$ & $-0.21 * * *$ & $-0.21^{\text {**** }}$ \\
\hline \multicolumn{4}{|c|}{ Worry on medical care } \\
\hline \multicolumn{4}{|c|}{ Not worried (reference) } \\
\hline Worried & $0.86^{* * * *}$ & 0.71 **** & 1.43 \\
\hline
\end{tabular}


TABLE 4 (continued)

\begin{tabular}{|c|c|c|c|}
\hline Covariate & Model I & Model 2 & Model 3 \\
\hline \multicolumn{4}{|l|}{ Marital status } \\
\hline \multicolumn{4}{|l|}{ Currently not married (reference) } \\
\hline Currently married & & -0.46 & -0.45 \\
\hline \multicolumn{4}{|l|}{ Number of children } \\
\hline \multicolumn{4}{|l|}{ One child (reference) } \\
\hline Two children & & 0.38 & -0.10 \\
\hline Three children & & 0.41 & 0.05 \\
\hline Four children & & 0.52 & -0.23 \\
\hline Five or more & & 0.50 & -0.28 \\
\hline \multicolumn{4}{|l|}{ Living arrangements } \\
\hline \multicolumn{4}{|l|}{ Together not for help (reference) } \\
\hline Together for help & & -0.14 & -0.17 \\
\hline Same street committee & & -0.05 & -0.02 \\
\hline Not same street committee & & -0.16 & -0.18 \\
\hline \multicolumn{4}{|l|}{ Financial support } \\
\hline \multicolumn{4}{|l|}{ No (reference) } \\
\hline Yes & & -0.20 & -0.20 \\
\hline \multicolumn{4}{|l|}{ In-kind gifts } \\
\hline \multicolumn{4}{|l|}{ No (reference) } \\
\hline Yes & & -0.47 水水 & $-0.48^{*}$ 冰 \\
\hline \multicolumn{4}{|l|}{ Help with daily activities } \\
\hline \multicolumn{4}{|l|}{ No (reference) } \\
\hline Yes & & -0.20 & -0.21 \\
\hline \multicolumn{4}{|l|}{ Emotional support } \\
\hline \multicolumn{4}{|l|}{ Not satisfied (reference) } \\
\hline Satisfied & & $-1.11^{*}$ *** & 0.13 \\
\hline Very satisfied & & $-1.55^{*}$ *水* & -0.11 \\
\hline \multicolumn{4}{|l|}{ Interaction with worry on medical care } \\
\hline Two Children-Worried & & & 0.88 \\
\hline Three Children-Worried & & & 0.56 \\
\hline Four Children-Worried & & & $1.43^{*}$ \\
\hline Five or More Children-Worried & & & $1.60^{*}$ \\
\hline Satisfied Emotional Support_-Worried & & & $-1.63^{*}$ \\
\hline Very Satisfied Emotional Support-Worried & & & -2.38 *** \\
\hline
\end{tabular}

NOTE: Estimates of variance and covariance components are the same as presented in Table 3 . $*^{*} p<.05$. *** $p<.01$. **** $p<.001$.

Regarding control variables, older ages are associated with lower level of affective symptoms but are not related to somatic symptoms. Whereas they have a lower level of somatic symptoms than the female elders, the male elders have a higher level of affective symptoms than their female counterparts, with the former difference much exceeding the latter. It seems that the male benefit for the overall depression mea- 
sure is from their overriding advantage in the manifestation of fewer somatic symptoms. The marginal effect of the highest level of education is mainly reflected in its effect on somatic measures. Income satisfaction shows similar effects on both depressive symptoms. Physical health status is negatively related to both sets of depressive symptoms. Its effect is consistent and highly significant across all the models.

Finally, the joint models provide estimates of the three components of the covariance matrix, $\Sigma$. The estimated covariance between the error terms of the two dimensions of depression is highly significant across all the models, suggesting that somatic and affective symptoms are closely correlated even after all the observed covariates are taken into account. The finding confirms the necessity of adopting such a joint modeling approach.

\section{Discussion}

Extending previous studies on depression of the Chinese elders, which tend to focus on financial strain, this study introduces perceived adequacy of public medical care as a potential source of stress and places the investigation of the role of family support in a broader social context.

With the transition from a planned to a market economy, China has achieved dramatic economic growth, which lifts personal income and living standards, especially in urban areas. Ironically, such rapid economic development, rather than strengthening, weakened the security of public medical care, a trend that is likely to continue. As disparity in income increases, the new fee-for-service system raises barriers to basic health care for many urban elders (Hsiao and Liu 1996). The results indicate that decreased access to universally provided public medical care is a widespread concern among Chinese elders and that the elders' perception of the adequacy of medical care coverage has a substantial impact on their well-being. The fact that worry about medical care remains significant even after income satisfaction is taken into account suggests its independent effect beyond common financial strain. One implication of this study is that the impact of inadequate medical care coverage resulting from these social changes cannot be overlooked in either policy or research arenas. 
In the face of stress from uncertain public medical care, of all family support measures, emotional support from children is found to have significant buffering effects on the elders' depression. There is a clear positive correlation between the level of such support and reduction in the impact of worry about medical care. Such a pattern is observed for all depression measures examined in this study. The elders who are most satisfied with emotional support are best protected against the detrimental effect of perceived insufficient medical care coverage.

Other instrumental support measures, such as financial transfer, in contrast, do not show a very strong association with the elders's psychological well-being. This is consistent with some previous findings. Whereas emotional support exerted a significant effect on both somatic and affective symptoms, economic support did not produce any significant impact (Krause and Liang 1993). This may be accounted for by the following reasons: First, the "support mobilization" mechanism (George 1996), in which instrumental assistance acts as a response to the status of health, may blur the positive effect of financial support on well-being. Second, it has been argued that receiving help may erode one's sense of control, which in turn may actually increase depression. Krause et al.'s (1998) study of the Chinese elders in Wuhan City found that it was anticipated support, rather than received support, that reduced the impact of financial strain on the level of depression. Although receiving support may bring about a sense of guilt, the existence of anticipated support makes the elders feel secure and believe there will be others ready to help if anything arises in the future.

The findings regarding the effects of the number of children seem to be at odds with the notion of "more children, more happiness." There are interaction effects between the number of children and worry about medical care for both the overall depression score and affective symptoms, but the effects are not in the beneficial direction. The elders with more than four children are more affected by their worry about medical care than those with fewer children. One possible explanation is that as the size of a network increases, so does the possibility of conflict. This is consistent with what has been documented in the literature: Networks of small size and strong ties were found to be associated with well-being (House et al. 1988). An alter- 
native explanation is that large families share some unfavorable characteristics, such as low social status, which are detrimental to the elders' well-being. In preliminary analysis, children's average income of each family was calculated and transferred into a $Z$-score of the whole sample to represent family economic status, but its effect was not significant. However, reported income is usually not a reliable measure of actual economic status in China, because it does not include various kinds of benefits, like medical care coverage and housing subsidies, or any other hidden sources of income. Furthermore, other family characteristics may also be important. Therefore, this line of explanation cannot be totally ruled out.

Although living arrangements only show some marginal effects, the effects are consistent between Model 2 and Model 3 for somatic symptoms. The findings suggest that living in the same neighborhood committee as children is associated with better well-being than either living with children in the same household or living further from children. This is again incompatible with the ideal image of "four generations under the same roof." However, it is still too early to conclude whether this reflects a desire of the elders for independence or privacy, or whether this is consistent with avoiding conflict. More recent data are needed to explore this association.

The findings regarding the role of family support reveal two important themes: First, the findings confirm the notion that functional support is more important than structural measures of family network. The major force in buffering the negative effect of worry about medical care is the emotional support that the elders received. This is consistent with findings in the literature (Pinquart and Sorensen 2000). Second, the patterns of the effects of family support are complex rather than simple. Not all family support measures show consistently positive effects on the elders' well-being. And even the effect of one variable is not always linear.

Nevertheless, this study confirms that family ties play a critical role in buffering the impact of undesirable social events in the wake of socioeconomic transformation in China. In light of family planning policy in China, however, total reliance on family support may not be a promising solution. China's fertility rate has declined dramatically, with the one-child policy more strictly implemented in urban areas. Adult sons and daughters in single-child families will face two pairs of 
parents to support (Zeng 1986), and their capability to provide traditional family support is likely to be challenged. As a result of reduced familial sources of immediate support, there will be an escalation of demand for formal assistance. Therefore, an effective and long-term solution is to establish social welfare programs, including adequate public medical care coverage, to meet the increasing needs of an aging population.

Some new trends in China's welfare programs have emerged in the past decade, such as "socialized" social welfare that separates individual enterprises from welfare programs and a shift in responsibilities for social welfare services to the market sector and to nongovernment organizations (Croll 1999). There has also been official encouragement of informal neighborhood services to bridge the gap between welfare demand and supply. The effects of these social changes on the well-being of the urban elders need to be carefully monitored.

Methodologically, this study provides some support for differentiating depression between somatic and affective domains. Each shows some unique associations with family support and other individual characteristics. The joint modeling approach proved to be appropriate in analyzing the two correlated symptoms.

Finally, due in part to the cross-sectional design of the survey, this study is not without limitations. In research on the relationship between social support and well-being, one of the biggest challenges is to disentangle the causal order (House 1981; Lin, Woelfel, and Light 1985; Lin et al. 1999; Thoits 1982). Because there is a mutual relationship between these two constructs, their causal relationship in crosssectional data can be ambiguous. Therefore, caution should be exercised in interpreting relationships. There is also the possibility of an endogeneity bias for the core independent variable, worry about medical care, which, in some cases, may be a response to the depressed mood caused by other forms of stress. It would be ideal to have both objective and subjective measures of medical care coverage and to be able to explore the relationships between them and their unique effects on depression. Carefully designed longitudinal studies are called for to further understanding of these dynamic processes. 


\section{APPENDIX Selected Survey Questions}

Questions on Depression

Question 1: "For each of the following statements, please tell me whether you ever felt or behaved in this way. I'd like to know, during the past week, whether you often, sometimes, rarely, or never had this experience."

I worried about little things.

I did not feel like eating.

I had trouble keeping my mind on what I was doing.

I felt very happy.

I felt lonely.

I felt depressed.

I felt life was pleasant.

I thought my life had been a failure.

I felt that some people disliked me.

I felt full of energy.

I did not sleep well.

I could not find the energy to do things.

I felt that everything I did was an effort.

I felt this was the best time of my life.

\section{Questions on Health Status}

Question 2: "Please tell me what illness or symptoms of poor health you currently have. How much influence has this illness (symptom) created for your daily activities?" (Up to eight reported symptoms recorded)

$$
\begin{aligned}
& 1=\text { not at all } \\
& 2=a \text { little } \\
& 3=a \text { great deal }
\end{aligned}
$$

Question 3: "Now I will ask you whether you have any difficulties in doing the following activities. Do you have no difficulty, a little difficulty, a lot of difficulty, or are you unable to do this activity?"

Shopping for personal items

Climbing 2 to 3 flights of stairs

Walking 200 to 300 meters 
Lifting or carrying something as heavy as 10 kilos

Using hands to open a tightly closed jar

Being on feet for about two hours

Getting on bus

Question 4: "How would you rate your health at the present time? Would you say it is very good, good, average, not very good, or very poor?"

\section{Questions on Family Support}

There are two optional answers (yes/no) to all the following questions.

Question 5: "Is there anyone who currently helps you with bathing, dressing, or going to the bathroom?"

Question 6: "Is there anyone who currently helps you with household chores, shopping, meal preparation, taking buses, or managing finances?"

Question 7: "Is anyone who currently gives money to help you (and your (wife/husband))?"

Question 8: "Is there anyone who currently gives food or clothing or other goods to help you?"

\section{NOTES}

1. Feeling disliked, reflecting the interpersonal dimension, was dropped in constructing separate measures. Interpersonal dimension measures were found to be the least associated with the overall measure of depression (Radloff 1977). For those cases $(n=39)$ with only one missing value on all the 14 items, the average value of the existent 13 items is computed and added to the total score.

2. The reliability coefficient alpha is usually acceptable when it is .70 or above (Nunnally 1978).

3. The results of factor analysis partially support this treatment. The results suggest a twofactor pattern: with the 3 positive affective items forming one factor, with the rest of the 13 items forming the other (somatic symptoms and negative affective items are lumped together). When the three negative affective symptoms are removed, the result largely confirms the two-factor scenario.

4. Results with the original three categories show similar patterns.

5. Help with daily activities, based on two questions, refers to help with bathing, dressing, shopping, preparing meals, and so on. 
6. The last category combines dissatisfied and very dissa tisfied, because there were only 4 respondents expressing very dissatisfied emotional support.

7. For those cases $(n=88)$ with only one of the seven items missing, the average value of the existent six items is computed and added to the total score.

\section{REFERENCES}

Bartlett, Dean. 1998. Stress: Perspectives and Processes. Philadelphia: Open University Press. Beijing Review. 1997. "Issues of Most Concern to Urban Workers." Beijing Review 40:21.

Chen, Xuan and Merril Silverstein. 2000. "Intergenerational Social Support and the Psychological Well-Being of Older Parents in China." Research on Aging 22:43-65.

Chi, Iris and Kee-Lee Chou. 1999. "Financial Strain and Depressive Symptoms Among Hong Kong Chinese Elderly: A Longitudinal Study." Joumal of Gerontological Social Work 32:41-60.

_. 2001. "Social Support and Depression Among Elderly Chinese People in Hong Kong." International Joumal of Aging and Human Development 52:231-52.

Chou, Kee-Lee and Iris Chi. 2001. "StressfulLife Events and Depressive Symptoms: Social Support and Sense of Control as Mediators or Moderators?" International Journal of Aging and Human Development 52:155-71.

Cockerham, William C. 1999. Health and Social Change in Russia and Eastern Europe. New York: Routledge.

Croll, Elizabeth J. 1999. "Social Welfare Reform: Trends and Tensions." China Quarterly 159:684-99.

Davis, Deborah. 1989. "Chinese Social Welfare: Policies and Outcomes." China Quarterly 119:577-97.

George, Linda K. 1996. "Social Factors and Ilness." Pp. 229-52 in Handbook of Aging and the Social Sciences, edited by R. H. Binstock and L. K. George. New York: Academic Press.

Gui, Shi-Xun, Li-Kui Li, Zhe-Ning Shen, Jue-Xin Di, Quan-Zhong Gu, Yang-Ming Chen, and Fang Qian. 1987. "Stat us and Needs of the Elderly in Urban Shanghai: Analysis of SomePreliminary Statistics." Joumal of Cross-Cultural Gerontology 2:171-86.

Hong, Li and Martin B. Tracy. 1999. "Family Support, Financial Needs, and Health Care Needs of Rural Elderly in China: A Field Study." Joumal of Cross-Cultural Gerontology 14:357-71.

House, James S. 1981. Work Stress and Social Support. Reading, MA: Addison-Wesley.

House, J. S. and Cynthia Robbins. 1983. "Age, Psychosocial Stress, and Health." Pp. 175-98 in Aging in Society: Selected Reviews of Recent Research, edited by M. W. Riley, B. B. Hess, and K. Bond. Hillsdale, NJ: Lawrence Erlbaum.

House, James S., Debra Umberson, and Karl R.Landis. 1988. "Social Relationships and Health." Science 241:540-45.

Hsiao, William C. L. and Yuanli Liu. 1996. "Economic Reform and Health-Lessons from China." The New England Joumal of Medicine 335:430-32.

Kleinman, Arthur M. 1977. "Depression, Somatization and the "New Cross-Cultural Psychiatry." Social Science \& Medicine 11:3-10.

Krause, Neal and Jersey Liang. 1992. "Cross-Cultural Variations in Depressive Symptoms in Later Life." International Psychogeriatrics 4:185-202.

- 1993. "Stress, Social Support, and PsychologicalDistress Among the Chinese Elderly." Journal of Gerontology 48:282-91. 
Krause, Neal, Jerseu Liang, and Shengzu Gu. 1998. "Financial Strain, Received Support, Anticipated Support, and Depressive Symptoms in the People's Republic of China." Psychology of Aging 13:58-68.

Liang, Jersey and Shengzu Gu. 1989. "Long-Term Care for the Elderly in China." Pp. 265-87 in Caring for an Aging World, edited by T. Schwab. New York: McGraw-Hill.

Lin, Nan, Mary W. Woelfel, and Stephen C. Light. 1985. "The Buffering Effect of Social Support Subsequent to an Important Life Event." Joumal of Health and Social Behavior 26:247-63.

Lin, Nan, Xiaolan Ye, and Walter M. Ensel. 1999. "Social Support and Depressed Mood: A Structural Analysis." Journal of Health and Social Behavior 40:344-59.

Littell, Ramon C., George A. Millliken, Walter W. Stroup, and Russell D. Wolfinger. 1996. SAS System for Mixed Models. Cary, NC: SAS Institute.

Marsella, Anthony J. 1987. "The Measurement of Depressive Experience and Disorder Across Cultures." Pp. 376-97 in The Measurement of Depression, edited by A. J. Marsella, R. M. A. Hirschfeld, and M. M. Katz. New York: Guilford.

Moody, Harry R. 2000. Aging Concepts \& Contraversies. Thousand Oaks, CA: Pine Forge Press.

Nunnally, Jum C. 1978. Psychometric Theory. New York: McGraw-Hill.

Pearlin, Leonard I. 1989. "The Sociological Study of Stress." Journal of Health and Social Behavior 30:241-56.

Pearlin, Leonard I., Elizabeth G. Menaghan, Morton A. Lieberman, and Joseph T. Mullan. 1981. "The Stress Process." Journal of Health and Social Behavior 22:337-56.

Pei, Xiaomei and Vijayan K. Pillai. 1999. "Old Age Support in China: The Role of the State and the Family." International Joumal of Aging and Human Development 49:197-212.

Pinquart, Martin and Silvia Sorensen. 2000. "Influences of Socioeconomic Status, Social Network, and Competence on Subjective Well-Being in Later Life: A Meta-Analysis." Psychology and Aging 15:187-224.

Press, S. James. 1972. Applied Multivariate Analysis. New York: Holt, Rinehart \& Winston.

Radloff, Lenore S. 1977. "The CES-D Scale: A Self-Report Depression Scale for Research in the General Population." Applied Psychological Measurement 1:385-401.

Tausig, Mark and Rudy Fenwick. 1999. "Recession and Well-Being." Journal of Health and Social Behavior 40:1-16.

Thoits, Peggy A. 1982. "Conceptual, Methodological, and Theoretical Problems in Studying Social Support as a Buffer Against Life Stress." Journal of Health and Social Behavior 23:145-59.

Wheaton, Blair. 1985. "Models for the Stress-Buffering Functions of Coping Resources." Journal of Health and Social Behavior 26:352-64.

Whyte, Martin K. 2003. "China's Revolutions and Intergenerational Relations." Pp. 3-30 in China's Revolutions and Intergenerational Relations, edited by M. K. Whyte. Ann Arbor: Center for Chinese Studies, University of Michigan.

Woo, J., S. C. Ho, J. Lau, Y. K. Yuen, H. Chiu, H. C. Lee, and I. Chi. 1994. "The Prevalence of Depressive Symptoms and Predicting Factors in an Elderly Chinese Population." Acta Psychiatrica Scandinavica 89:8-13.

Zeng, Yi. 1986. "Changes in Family Structure in China: A Simulation Study." Population and Development Review 12:675-703.

Zeng, Yi and James W. Vaupel. 2002. "Functional Capacity and Self-Evaluation of Health and Life of Oldest Old in China." Journal of Social Issues 58:733-48.

Zhang, Wenfan. 1997. "Population Aging and Its Strategic Options." China Population Today $14: 2$.

Zhu, Chuanyi and Qin Xu. 1992. "Family Care of the Elderly in China: Changes and Problems." Pp. 67-81 in Family Care of the Elderly: Social and Cultural Changes, edited by J. I. Kosberg. Newbury Park, CA: Sage. 
Rongjun Sun is an assistant professor in the Department of Sociology at Cleveland State University. His research interests include aging, family relations, and research methods. He is currently investigating American family lineage structures and health of the oldest-old in China. 